\title{
Anomalous Solubility Behavior of Several Acidic Drugs
}

\author{
Alex Avdeef \\ in-ADME Research, 1732 First Avenue, \#102, New York, NY 10128, USA \\ E-mail: alex@in-ADME.com; Tel.: +1 6466785713
}

Received: January 27, 2014; Revised: March 12, 2014; Published: April 01, 2014

\begin{abstract}
The "anomalous solubility behavior at higher $\mathrm{pH}$ values" of several acidic drugs originally studied by Higuchi et al. in 1953 [1], but hitherto not fully rationalized, has been re-analyzed using a novel solubility-

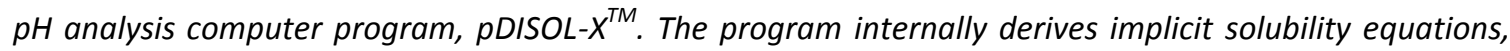
given a set of proposed equilibria and constants (iteratively refined by weighted nonlinear regression), and does not require explicit Henderson-Hasselbalch equations. The re-analyzed original barbital, phenobarbital, oxytetracycline, and sulfathiazole solubility-pH data of Higuchi et al. is consistent with the presence of dimers in saturated solutions. In the case of barbital, phenobarbital and sulfathiazole, anionic dimers, reaching peak concentrations near $\mathrm{pH}$ 8. However, oxytetracycline indicated a pronounced tendency to form a cationic dimer, peaking near $\mathrm{pH}$ 2. Under the conditions of the original study, only barbital indicated a slight tendency to form a salt precipitate at $\mathrm{pH}>6.8$, with a highly unusual stoichiometry (consistent with a slope of 0.55 in the log $S-p H$ plot): $K^{+}+A_{2} H^{-}+3 H A \leftrightarrows K A_{5} H_{4}(s)$. Thus the "anomaly" in the Higuchi data can be rationalized by invoking specific aggregated species.
\end{abstract}

\section{Keywords}

Sparingly-soluble drugs; pH-dependent solubility; salt solubility products; solubility equations; aggregation; shake-flask method.

\section{Introduction}

Aggregation and micelle formation of drugs in a saturated solution can complicate the interpretation of the solubility measurements, especially when the molecules are ionizable. There are many reports of such systems [1-6]. For example, doxycycline [3], with intrinsic solubility $S_{0}=0.72 \mathrm{mg} / \mathrm{mL}$, at $25^{\circ} \mathrm{C}$ in $1 \mathrm{M}$ $\mathrm{NaCl} / \mathrm{HCl}$ solutions ( $\mathrm{pH} 0$ to 6 ), forms dimers with $\mathrm{K}_{2}=24 \mathrm{M}^{-1}$. Such aggregates were found to have unusually high and temperature-sensitive solubility. Zhu and Streng [4] found that the self-association of dolasetron to form cationic dimers and trimers was enthalpy driven ( $\mathrm{H}$-bond/aromatic ring rather than hydrophobic/electrostatic interactions), with the aggregation constants, $\mathrm{K}_{2-3}$, ranging from 4 to $50 \mathrm{M}^{-1}$ at $25^{\circ} \mathrm{C}$. Many nonsteroidal antiinflammatory drugs [5], such as indomethacin, diclofenac, ibuprofen, ketoprofen, naproxen, and sulindac, can self-associate by forming mixed-charge micelle or micelle-like structures. The reported CMC of diclofenac is about $25 \mathrm{mM}$ and of ketoprofen is about $160 \mathrm{mM}$ [5]. The solubility-pH profiles cannot be accurately described with the Henderson-Hasselbalch equation when aggregates form $[2,6]$. 
The objective of this brief commentary is to address the "anomalous solubility behavior at higher $\mathrm{pH}$ values" of several ionizable drugs studied by Higuchi et al. in 1953 [1], but hitherto not fully understood. The measured solubility-pH profiles of two barbiturates (phenobarbital, barbital) and two ampholytes (oxytetracycline and sulfathiazole) showed anomalous shapes, which could not be accurately described by the Henderson-Hasselbalch equations. Analysis of the data using a new program, $p D I S O L-X$, suggested the presence of anionic (mixed-charge) dimers, $\mathrm{AHA}^{-}$, in the case of the barbiturates and sulfathiazole and very stable cationic (mixed-charge) dimers, $\mathrm{XH}_{2} \cdot \mathrm{XH}_{3}{ }^{+}$, in the case of oxytetracycline. Higuchi et al. noted that between pH 6.8 and 7.1, the slope in the log $S$ vs. pH plot for barbital had a value of +0.55 , but no concrete explanation was offered. They also noted the oxytetracycline between $\mathrm{pH} 2$ and 5 had a slope of -0.91 , which would not have been expected for a simple system. The values of the $\mathrm{p} K_{\mathrm{a}}$ of the molecules were not reported in the study. Had accurate $\mathrm{p} K_{\mathrm{a}}$ values been discussed, then other anomalies in the solubility data would have been evident at that time.

\section{Experimental}

Legacy Data

In the Higuchi et al. study [1], $\mathrm{pH}$ was adjusted by the addition of standardized $\mathrm{HCl}$ or $\mathrm{KOH}$ to buffer-free suspensions containing 10-30 \% excess solid over the saturation concentration. The ionic strength was well controlled with $0.15 \mathrm{M} \mathrm{KCl}$, and the temperature was maintained at $25{ }^{\circ} \mathrm{C}$ ( $30{ }^{\circ} \mathrm{C}$ in one case). The equilibration times ranged from one to eight days, after which the final $\mathrm{pH}$ had been measured.

\section{Refinement of Intrinsic and Salt Solubility and Aggregation Constants}

Detail of the mathematical approach in the $p$ DISOL-X computer program has been described by Völgyi et al. [6]. Briefly, the new data analysis method uses $\log S-\mathrm{pH}$ as measured input data from any analytical technique (along with standard deviations, $\mathrm{SD}(\log S)$ ) into $\mathrm{pDISOL-X.} \mathrm{An} \mathrm{algorithm} \mathrm{was} \mathrm{developed} \mathrm{which}$ considers the contribution of all species proposed to be present in solution, including universal buffer components (e.g., Britton-Robinson). The approach does not depend on any explicitly derived extensions of the Henderson-Hasselbalch equations. The computational algorithm derives its own implicit equations internally, given any practical number of equilibria and estimated constants, which are subsequently refined by weighted nonlinear least-squares regression $[2,6]$. Therefore, in principal, drug-salt precipitates, -aggregates, -complexes, - bile salts, -surfactant can be accommodated [2,6]. Presence of specific bufferdrug species can be tested. The program assumes an initial condition of a suspension of the solid drug in a solution, ideally with the suspension saturated over a wide range of $\mathrm{pH}$. The program calculates the distribution of species consequent to a sequence of additions of standardized strong-acid titrant $\mathrm{HCl}$ (or weak-acid titrants $\mathrm{H}_{3} \mathrm{PO}_{4}, \mathrm{H}_{2} \mathrm{SO}_{4}$, acetic acid, maleic acid, lactic acid) to simulate the suspension $\mathrm{pH}$ speciation down to $\mathrm{pH} \sim 0$, the staging point for the subsequent operation. A sequence of perturbations with standardized $\mathrm{KOH}$ is simulated, and solubility calculated at each point (in pH steps of 0.005-0.2), until $\mathrm{pH} \sim 13$ is reached. The ionic strength is rigorously calculated at each step, and $\mathrm{p} K_{\mathrm{a}}$ values (as well as solubility products, aggregation and complexation constants) are accordingly adjusted [6].

At the end of the $\mathrm{pH}$-speciation simulation, the calculated log $S$ vs. $\mathrm{pH}$ curve is compared to measured $\log S$ vs. $\mathrm{pH}$. A log $S$-weighted nonlinear least squares refinement commences to refine the proposed equilibrium model, using analytical expressions for the differential equations. The process is repeated until the differences between calculated and measured log $S$ values reach a minimum, as described elsewhere in detail $[2,6]$. 


\section{Results and Discussion}

The results of the analysis of the Higuchi et al. data are summarized in Table 1. All four drugs in the Higuchi study indicated the presence of singly-charged dimers in saturated solution of the free acid. A salt precipitate also formed in the case of barbital.

Table 1. Summary of the Results of the Re-Analysis of the Higuchi et al. [1] Data.

\begin{tabular}{|c|c|c|c|c|c|c|c|}
\hline COMPOUND & $\begin{array}{c}\mathrm{p} K_{\mathrm{a}} \\
\left(25^{\circ} \mathrm{C}, \mathrm{I}=0.15 \mathrm{M}\right)^{\mathrm{a}}\end{array}$ & $-\log S_{0}$ & $\begin{array}{c}S_{0} \\
(\mathrm{mg} / \mathrm{mL})\end{array}$ & $\begin{array}{c}\text { mixed-charge } \\
\text { dimer }\end{array}$ & $\log K_{2}\left(\mathrm{M}^{-1}\right)$ & $K_{2}\left(\mathrm{M}^{-1}\right)$ & GOF $^{b}$ \\
\hline Barbital $^{c}$ & 7.86 & $1.57 \pm 0.01$ & 5.00 & $\mathrm{HA}+\mathrm{A}^{-} \leftrightarrows \mathrm{A}_{2} \mathrm{H}^{-}$ & $2.17 \pm 0.03$ & $148 \pm 10$ & 0.12 \\
\hline Phenobarbital & 7.41 & $2.55 \pm 0.01$ & 0.66 & $\mathrm{HA}+\mathrm{A}^{-} \leftrightarrows \mathrm{A}_{2} \mathrm{H}^{-}$ & $2.43 \pm 0.04$ & $269 \pm 22$ & 0.22 \\
\hline Oxytetracycline & $8.82,7.22,3.23$ & $3.20 \pm 0.03$ & 0.29 & $\mathrm{XH}_{3}{ }^{+}+\mathrm{XH}_{2} \leftrightarrows \mathrm{X}_{2} \mathrm{H}_{5}{ }^{+}$ & $3.42 \pm 0.07$ & $2634 \pm 425$ & 0.75 \\
\hline Sulfathiazole & $7.12,2.30$ & $2.83 \pm 0.01$ & 0.37 & $\mathrm{HX}+\mathrm{X}^{-} \leftrightarrows \mathrm{X}_{2} \mathrm{H}^{-}$ & $1.50 \pm 0.10$ & $32 \pm 7$ & 0.12 \\
\hline
\end{tabular}

\section{Barbital}

The solid curve in Figure $1 \mathrm{a}$ is the log $\mathrm{S}$ vs. $\mathrm{pH}$ profile of barbital at $30^{\circ} \mathrm{C}$. The dashed curve in the figure was calculated using the Henderson-Hasselbalch equation, employing $\mathrm{p} K_{\mathrm{a}}$ of 7.86 . As can be seen, the latter equation does not predict the experimental points very well.

Figure $1 \mathrm{~b}$ shows the simulated titration curve (volume of $1 \mathrm{M} \mathrm{KOH}$ added per $\mathrm{mL}$ of suspension solution vs. $\mathrm{pH}$ ) for barbital that best describes the Higuchi data (discrete points). The amount of solid barbital added to $1 \mathrm{~mL}$ of water was taken as $250 \mathrm{mg}$ in the $p D I S O L-X$ data analysis. The flat region centered at $\mathrm{pH}$ 6.82 , bounded by two discontinuities, is due to the co-precipitates of free acid, HA(s), and complex salt, $\mathrm{KA}_{5} \mathrm{H}_{4}(\mathrm{~s})$, i.e., $\left[\mathrm{K}^{+}(\mathrm{HA})_{3} \mathrm{AHA}\right](\mathrm{s})$. This fixed-pH region is defined by the so called $\mathrm{p} K_{\mathrm{a}}{ }^{\mathrm{GIBBS}}[7,8]$. The free acid is the only precipitate present for $\mathrm{pH}<\mathrm{pK}_{\mathrm{a}}^{\mathrm{GIBBS}}$. It takes about $0.3 \mathrm{~mL} \mathrm{KOH}$ titrant to convert the free acid precipitate entirely into the salt form, as shown in Figure $1 \mathrm{~b}$. For $\mathrm{pH}>\mathrm{p} K_{\mathrm{a}}^{\mathrm{GIBBS}}, \mathrm{KA}_{5} \mathrm{H}_{4}(\mathrm{~s})$ is the sole precipitate, up to the peak $\mathrm{pH}$ 9.56, where the salt precipitate completely dissolves due to ionization leading to the formation of the anion, $\mathrm{A}^{-}$(Fig. 1d). Note that the width of the flat region of the titration curve (Fig. 1b), and hence the values of the $\mathrm{pK}_{\mathrm{a}}^{\mathrm{GIBBS}}$ and peak $\mathrm{pH}$ are conditional, since the extent of dimer formation depends on the amount of solid added to water. Under the conditions of the study, only barbital appeared to show a tendency to form a salt precipitate, consistent with the very unusual stoichiometry (slope of +0.55 in the log $\mathrm{S}-\mathrm{pH}$ plot): $\mathrm{KA}_{5} \mathrm{H}_{4}(\mathrm{~s}) \leftrightarrows \mathrm{K}^{+}+\mathrm{AHA}^{-}+3 \mathrm{HA}$, with $K_{\mathrm{sp}}=2.23 \times 10^{-8} \mathrm{M}^{5}$.

The above salt stoichiometry best rationalizes the log $S-\mathrm{pH}$ curve of barbital for $\mathrm{pH}>\mathrm{p} K_{\mathrm{a}}^{\mathrm{GIBBS}}$. The solubility curve (solid line) for $\mathrm{pH}<\mathrm{pK}_{\mathrm{a}}^{\mathrm{GIBBS}}(6.82)$ is horizontally displaced to lower $\mathrm{pH}$ by about one unit, without change in its shape, compared to that calculated using the Henderson-Hasselbalch equation (dashed line in Fig. 1a). This is consistent with the formation of a mixed-charge dimeric species, $\mathrm{AHA}^{-}$(in the saturated solution), which may be visualized as a conjugate of a free acid, $H A$, and the ionize species, $A^{-}$ (cf., Appendix). The $A H A^{-}$dominates in concentration over that of $A^{-}$up to $\mathrm{pH} 9$ (Fig. 1c). For $\mathrm{pH}>\mathrm{pK}_{\mathrm{a}}{ }^{\mathrm{GIBBS}}$, the $\log S$ curve takes on a slope of about +0.55 , as originally noted by Higuchi et al. This can be explained if a new precipitate replaces $H A(s)$. A reasonable choice might have been $K^{+} \cdot A^{-} A^{-}(s)$, since $A H A^{-}$is the dominant anion present in solution. However, the log $S$ curve is not well fitted with such a model. Further testing of the data could have assumed that the above salt precipitate also contained HA components. 
After a trial-and-error process, the best fit was found where three molecules of the free acid, $\mathrm{HA}$, and one molecule of $\mathrm{AHA}^{-}$combine with $\mathrm{K}^{+}$to form the putative solid with the unusual stoichiometry $\mathrm{K}^{+}(\mathrm{HA})_{3} \mathrm{AHA}^{-}(\mathrm{s})$. $p$ DISOL-X can easily consider new tentative species in the model development and quickly test the data against such species, without having to derive explicit new solubility equations. The method described in the Appendix A in [6] certainly could have been applied here to derive the explicit equation corresponding to the formation of $\mathrm{K}^{+}(\mathrm{HA})_{3} \mathrm{AHA}^{-}(\mathrm{s})$, but the resultant equation would have been quite complex and of limited general applicability.

Figure 1c shows the direct concentration of various barbital species as a function of $\mathrm{pH}$, while Figure $1 \mathrm{~d}$ illustrates the log concentration vs $\mathrm{pH}$ relationships. In alkaline solution, the monomeric species, $\mathrm{A}^{-}$, and the mixed-charge dimeric species, $\mathrm{AHA}^{-}$coexist, with the latter species reaching a maximum concentration at the peak pH 9.56 (Fig. 1c) and declining in concentration with further increases in pH.
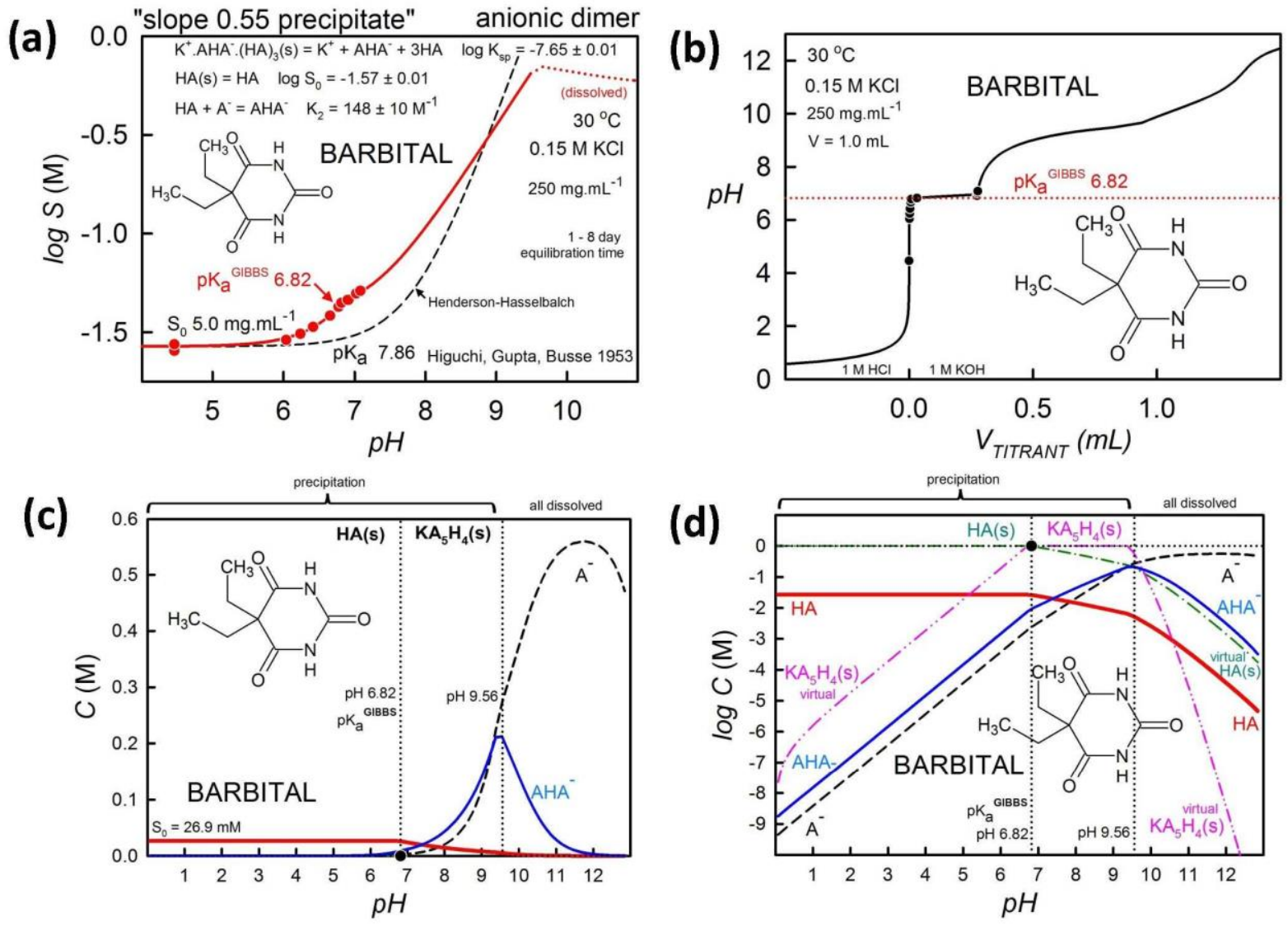

Figure 1. Barbital: (a) log S vs. pH; (b) titration curve; (c) concentration of species as a function of $\mathrm{pH}$; (d) log concentration of species as a function of $\mathrm{pH}$.

The above case study of barbital is an example of a general methodology to rationalize complicated $\log S-\mathrm{pH}$ profiles. In a simple "Henderson-Hasselbalch" precipitation process, the log $S$ curve does not depend on the quantity of solid added, as long as enough solid is added to maintain a saturated solution. However, if an aggregate, oligomer, or micelle-like drug forms, then the measured solubility can critically depend on the amount of solid added to solution. For example, suppose a micelle of the drug forms above the critical micelle concentration (CMC). A very poorly soluble drug can become better (self-) solubilized in high concentration $(>\mathrm{CMC}$ ). For example, this could explain why a parenteral formulation of amiodarone (high concentration) can stop atrial fibrillation in a few minutes post injection, whereas an oral formulation may take 30 days to reach full therapeutic effectiveness [9]. Being able to quantitate such concentration dependence (due to aggregate formation, etc.) could be a practically useful feature of $p D I S O L-X$ in drug 
development, to help predict dosing effects of poorly soluble molecules which form aggregates in solution.

\section{Phenobarbital}

Phenobarbital, which is about eight times less soluble than barbital, shows a similar solubility-pH profile in Figure $2 \mathrm{a}$ as that of barbital, except that no salt precipitate forms (the ratio of the octanol-water partition coefficients of the two molecules is also about eight). A dimeric species of the same stoichiometry forms as in the case of barbital, reaching maximum concentration at (conditional) pH of 7.82, as shown in Figure $2 \mathrm{~b}$ (the $\mathrm{pH}$-speciation simulation assumed the $5 \mathrm{mg}$ of solid had been added to $1 \mathrm{~mL}$ of water). The presence of the dimer is indicated by the shift of the log $S-\mathrm{pH}$ profile to the lower $\mathrm{pH}$ values above $\mathrm{pH}$, compared to that predicted by the Henderson-Hasselbalch equation.

(a)

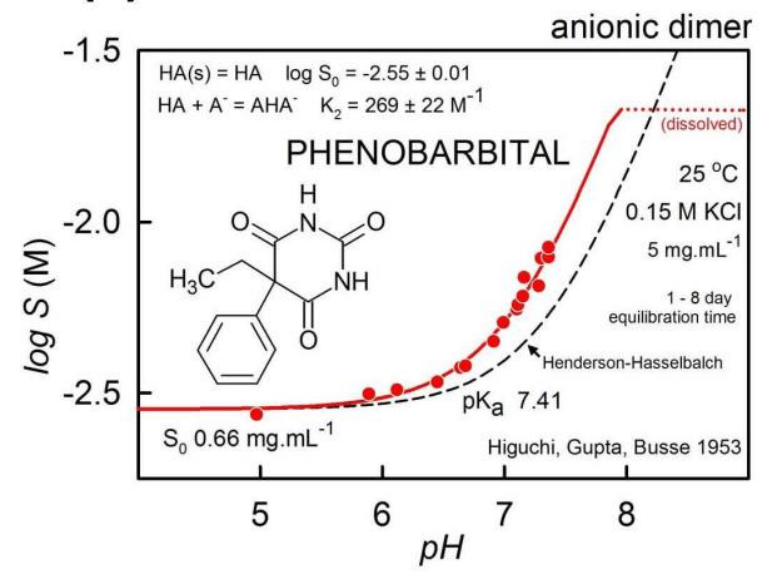

(b)

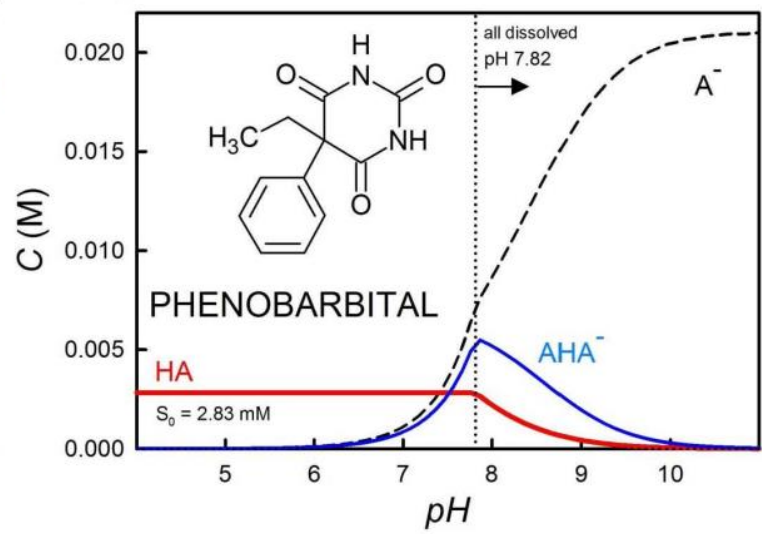

Figure 2. Phenobarbital: (a) log S vs. pH; (b) concentration of species as a function of $\mathrm{pH}$.

\section{Oxytetracycline}

Oxytetracycline is an ampholyte, whose ionizations can be described by three $\mathrm{p} K_{\mathrm{a}}$ values (Table 1$)$. Figure 3a shows the solubility-pH curve shifted to higher $\mathrm{pH}$ values below $\mathrm{pH} \mathrm{5,} \mathrm{compared} \mathrm{to} \mathrm{what} \mathrm{is}$ predicted by the Henderson-Hasselbalch equation. This is a pattern consistent with the presence of a cationic dimer formed from the neutral $\mathrm{XH}_{2}$ species and the cation $\mathrm{XH}_{3}{ }^{+}$. Many other shift patterns have been described in reference [2]. The cationic dimer maximized in concentration at (conditional) $\mathrm{pH} 1.63$, as shown in Figure 3b (the $\mathrm{pH}$-speciation simulation assumed that $50 \mathrm{mg}$ of solid had been added to $1 \mathrm{~mL}$ of water). 
(a)

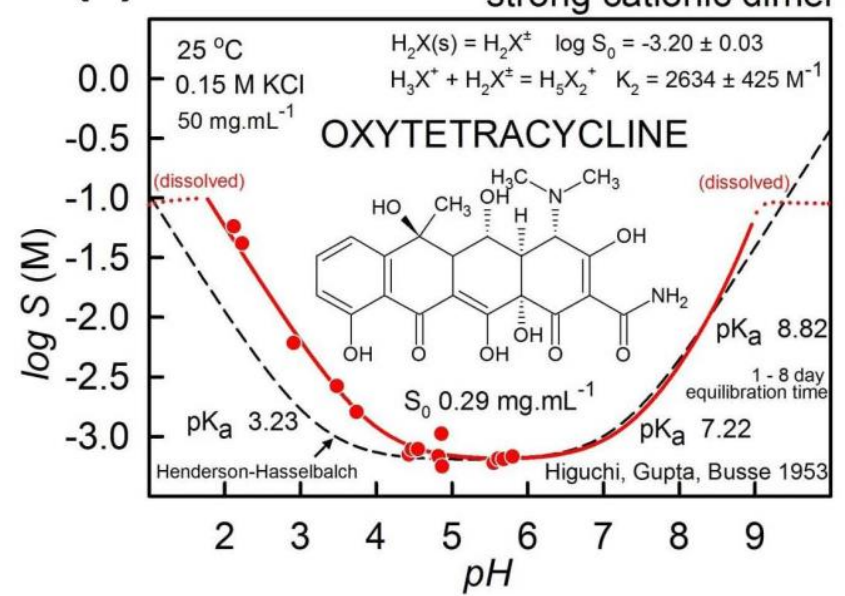

(b)

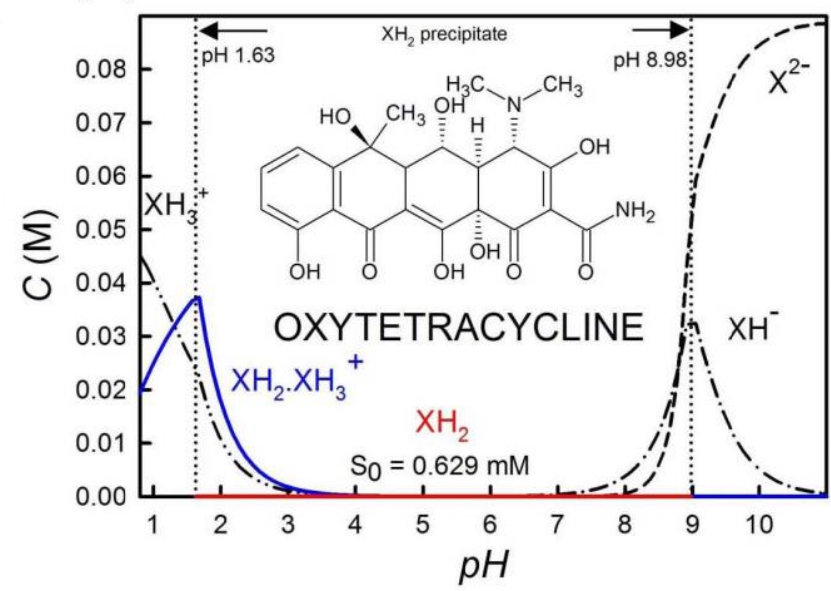

Figure 3. Oxytetracycline: (a) $\log S$ vs. $\mathrm{pH}$; (b) concentration of species as a function of $\mathrm{pH}$.

\section{Sulfathiazole}

The ampholyte sulfathiazole has the least tendency to form dimers, as suggested in Figure 4. A small quantity of anionic dimer appears to be consistent with the high precision data, whose concentration reaches a maximum at $\mathrm{pH}$ 8.16. Invoking the presence of a dimeric species under the circumstance would not be warranted ordinarily, were it not for the exceptionally high precision of the Higuchi et al. data.

(a)

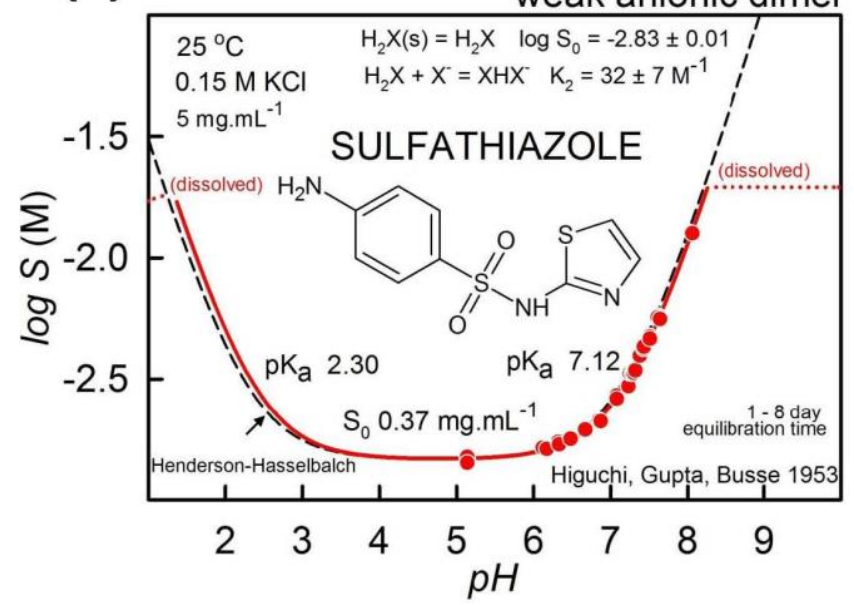

(b)

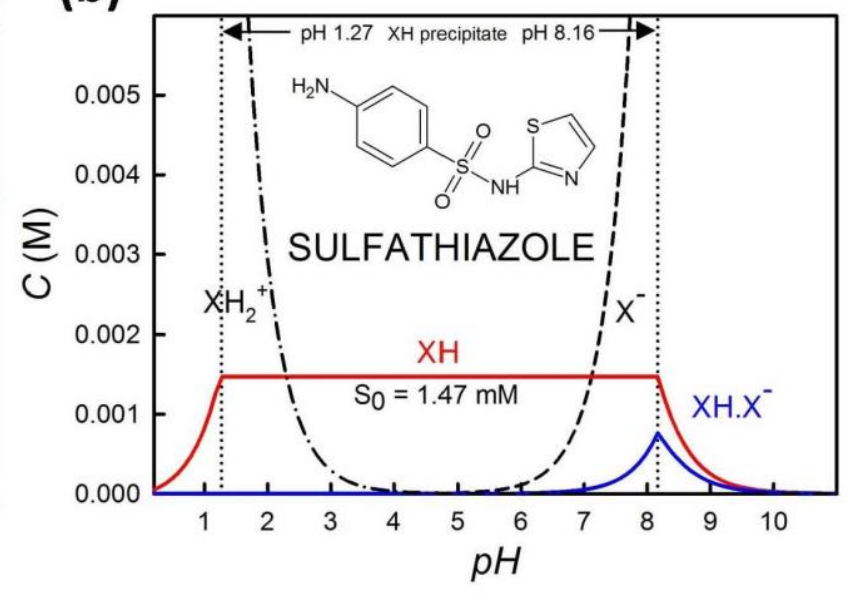

Figure 4. Sulfathiazole: (a) $\log S$ vs. $\mathrm{pH}$; (b) concentration of species as a function of $\mathrm{pH}$.

\section{Conclusions}

In the $p$ DISOL-X analysis, the "anomaly" in the Higuchi et al. 1953 data could be explained by presence of anionic dimers in three cases, and by the strong presence of a cationic dimer in the case of oxytetracycline, and also by the barbital salt precipitate that exhibits the slope of +0.55 . Apparently, these species were either not recognized originally, or were not fully characterized. Such anomalies can be common with sparingly-soluble drugs, but are not always easy to recognize. $p$ DISOL-X could be a helpful new tool to further aid in the analysis of dissolution mechanisms of sparingly-soluble drugs, since dissolution is closely linked to solubility. 
Acknowledgements: Helpful discussions with Gergely Völgyi and Krisztina Takács-Novák of Semmelweis University (Budapest) are greatly appreciated.

\section{References}

[1] T. Higuchi, M. Gupta, L.W. Busse. J. Am. Pharm. Assoc. 42 (1953) 157-161.

[2] A. Avdeef. Absorption and Drug Development Second Edition, Wiley-Interscience, Hoboken, NJ, 2012, pp. 251-318.

[3] J.B. Bogardus, R.K. Blackwood, Jr. J. Pharm. Sci. 68 (1979) 188-194.

[4] C. Zhu, W.H. Streng. Int. J. Pharm. 130 (1996) 159-168.

[5] A. Fini, G. Fazio, G. Feroci. Int. J. Pharm. 126 (1995) 95-102.

[6] G. Völgyi, A. Marosi, K. Takács-Novák, A. Avdeef. ADMET \& DMPK 1(4) (2013) 48-62.

[7] W.H. Streng. Int. J. Pharm. 186 (1999) 137-140.

[8] A. Avdeef. Pharm. Pharmacol. Commun. 4 (1998) 165-178.

[9] Amiodarone-containing parenteral solution patent: EP 1267865 B1 (15 Feb 2006). 


\section{Appendix}

\section{Shape Pattern Interpretation in Solubility Profiles for Sparingly-Soluble lonizable Weak Acids}

An important part of the analysis of solubility profiles involves recognizing characteristic shapes and interpreting these in terms of an equilibrium model [2]. Figure 5 shows the results of a series of simulations of a weak acid, $\mathrm{MW} 500 \mathrm{~g} / \mathrm{mol}$, having the same $\mathrm{p} K_{\mathrm{a}}=7$ and $\mathrm{p} S_{0}=3$, but having different combinations of salt and aggregate formations. In the first frame, $50 \mathrm{mg}$ of solid free acid were added to $1 \mathrm{~mL}$ of $0.15 \mathrm{M} \mathrm{KCl}$ solution. In the rest of the frames, $1500 \mathrm{mg}$ were added. The calculated average ionic strength is indicated in red at the bottom right of each frame. The dashed curves in the figures are calculated from the Henderson-Hasselbalch equation using the $\mathrm{p} K_{\mathrm{a}}$ and $\mathrm{p} \mathrm{S}_{0}$ constants. The solid lines are the actual log $\mathrm{S}$ curves, where either the free acid or the salt is precipitated. The $\mathrm{pH}$ at which both the free acid and the salt coprecipitate is the $\mathrm{pK}_{\mathrm{a}}{ }^{\mathrm{GIBBS}}$ (Figs. $5 \mathrm{~b}-\mathrm{d}$ ). In cases where $\mathrm{pH}$ is raised past the point where the entire solid dissolves, the curve is indicated by a dotted line (Figs. 5a,e,f).

(a)

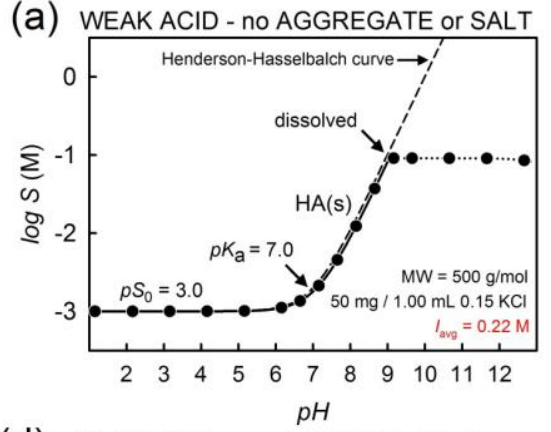

(d) WEAK ACID - neutral AGGREGATE

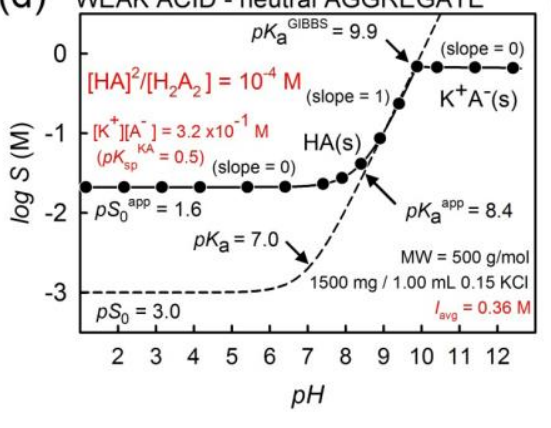

(b) WEAK ACID - K ${ }^{+} A^{-}$SALT

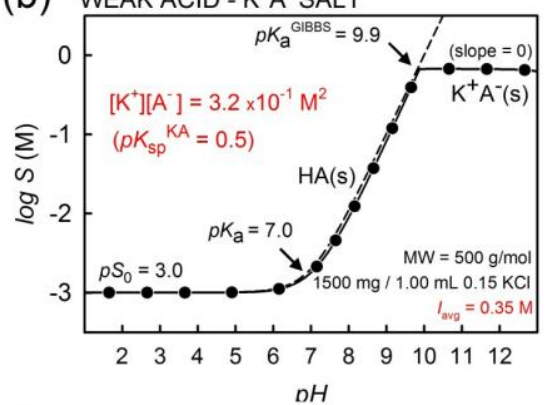

(e) WEAK ACID - AHA' AGGREGATE

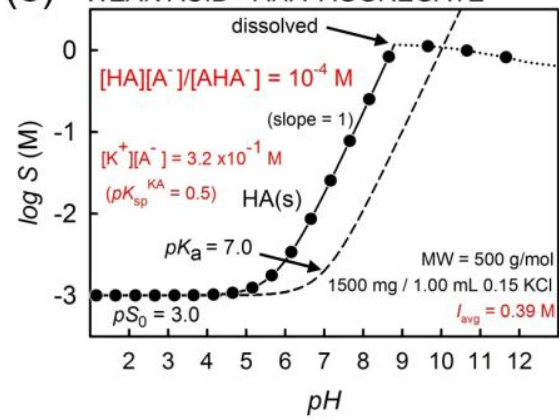

(c) WEAK ACID - K ${ }^{+} A H A \cdot$ SALT

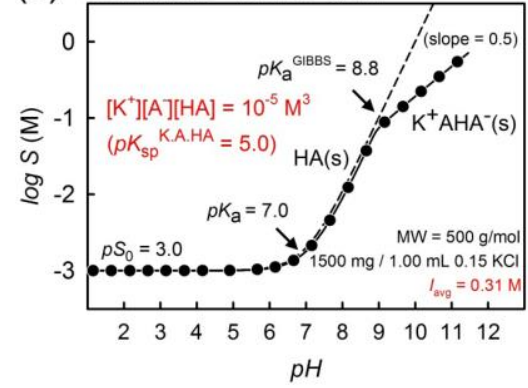

(f) WEAK ACID - strong $A_{3}^{3 .}$ AGGREGATE

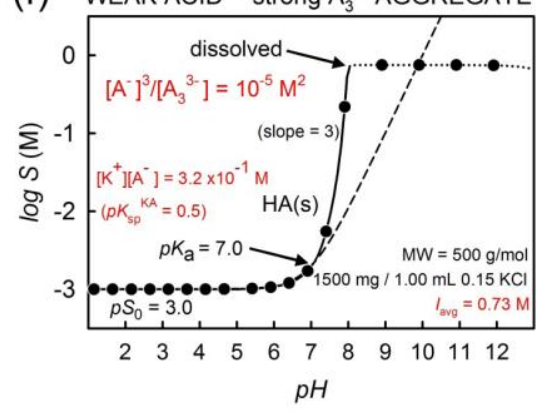

Figure 5. Simulations of various cases of free acid $\log S-\mathrm{pH}$ curves where salt precipitates or where aggregates form (see text).

Figure 5a is the simplest case, with no salt precipitate and no aggregates. The Henderson-Hasselbalch equation describes the $\log S-\mathrm{pH}$ profile as long as the solution remains saturated. Figures $5 \mathrm{~b}-\mathrm{d}$ show the shape of the profiles as $\mathrm{K}^{+} \mathrm{A}^{-}(\mathrm{s})$ or $\mathrm{K}^{+} \mathrm{AHA}^{-}(\mathrm{s})$ salts precipitate for $\mathrm{pH} \geq \mathrm{pK}_{\mathrm{a}}{ }^{\text {GIBBS }}$. Notice that in Figure $5 \mathrm{c}$, the maximum solubility does not occur at $\mathrm{pH}=\mathrm{p} K_{\mathrm{a}}{ }^{\text {GIBBS }}$. In older literature, it had been popular to refer to $\mathrm{p} K_{\mathrm{a}}{ }^{\mathrm{GIBBS}}$ as " $\mathrm{pH}_{\max }$ ", but clearly, such nomenclature is misleading in some cases, such as when complex salts form, as in Figure $5 c[7,8]$. In Figures $5 d$ - $f$ cases, aggregates form, which elevates solubility in characteristic ways. In the case of neutral aggregates (Fig. $5 \mathrm{~d}$ ), the region of the intrinsic solubility $\left(\mathrm{pH}<\mathrm{p} K_{\mathrm{a}}\right)$ is raised due to the enhanced solubility of the neutral species. The apparent $p K_{a}$ is shifted to 8.4 from the true value of 7. In the cases of charged aggregates (Fig. $5 e, f$ ), the solubility product for $\mathrm{K}^{+} \mathrm{A}^{-}(\mathrm{s}$ ) is no longer exceeded (for $1500 \mathrm{mg} / \mathrm{mL}$ ), and the compound completely dissolves above about $\mathrm{pH}$ 8, due to the increased solubility in alkaline solution. Figure $5 \mathrm{e}$ is an example of a mixed-charge dimer formation, $\mathrm{AHA}$, where the solubility 
curve in the slope $=1$ region shifts to lower $\mathrm{pH}$ values compared to that predicted by the HendersonHasselbalch equation. In Figure 5f, an anionic trimer, $\mathrm{A}_{3}{ }^{3-}$, is indicated by the slope $=3$ in the diagonal region of the log $\mathrm{S}$ profile.

\section{Example of a Step by Step Model Construction and Refinement for lonizable Sparingly-Soluble Weak Acid}

The following is a brief description of a practical process for developing and refining an equilibrium model to describe the solubility behavior of sparingly soluble drugs.

1. Before starting to develop an equilibrium model for an ionizable molecule, it is first necessary to know the accurate value of the $\mathrm{p} K_{\mathrm{a}}$. Preferably, the $\mathrm{p} K_{\mathrm{a}}$ is determined by an independent technique (e.g., by potentiometry, spectrophotometry, or capillary electrophoresis - but not by solubility).

2. Plot the $\log S$ data as a function of $\mathrm{pH}$. With an accurate $\mathrm{p} K_{\mathrm{a}}$ value at hand, the log $S$ profile is inspected for its shape characteristics, to see if the profile resembles any of the template frames in Figure 5.

3. If the $\mathrm{p} K_{\mathrm{a}}$ appears to be higher from the true value (as indicated by the $\mathrm{pH}$ in the middle of the bend in the log $S$ curve), then either neutral aggregates form (Fig. $5 \mathrm{~d}$ ) or not enough time had been allowed for equilibrium to be reached. The $p S_{0}$ can be estimated (for acids) as $p S_{0}^{\text {app }}+\left(p K_{a}^{a p p}-p K_{a}\right)$ [2]. Select $\mathrm{H}^{+}+\mathrm{A}^{-} \leftrightarrows \mathrm{HA}, \mathrm{HA} \leftrightarrows \mathrm{HA}(\mathrm{s})$, and $2 \mathrm{HA} \leftrightarrows \mathrm{A}_{2} \mathrm{H}_{2}$ as the three equilibria to consider in the model, and associate $\mathrm{pK}_{\mathrm{a}}$ and $\mathrm{pS}_{0}$ with the first two equations. Take a guess on the third constant, e.g., assume it to be 3 (log units). Refinement will usually hone in on the appropriate value quickly enough if the equilibrium model is valid.

4. If the $\mathrm{p} K_{\mathrm{a}}$ appears to be lower than the true value, but the slope in the diagonal portion of the log $S$ profile is 1 , then a mixed-charge dimer (or higher order oligomer) may be present (cf., Fig 5e). The p $S_{0}$ can be estimated as solubility in the acidic region of the curve $\left(\mathrm{pH} \ll<K_{\mathrm{a}}\right)$. Select $\mathrm{H}^{+}+\mathrm{A}^{-} \leftrightarrows \mathrm{HA}, \mathrm{HA} \leftrightarrows$ $\mathrm{HA}(\mathrm{s})$, and $\mathrm{HA}+\mathrm{A}^{-} \leftrightarrows \mathrm{AHA}^{-}$as the three equilibria to consider in the model, and associate $\mathrm{pK}_{\mathrm{a}}$ and $\mathrm{pS}_{0}$ with the first two equations. Take a guess on the third constant, e.g., assume it to be 3 (log units).

5. If the $\mathrm{p} K_{\mathrm{a}}$ appears to be slightly lower than the true value, but the slope in the diagonal portion of the $\log \mathrm{S}$ profile is greater than 1 , then an anionic oligomer may be present, with the degree of aggregation equal to the value of the slope (cf., Fig 5f). The $\mathrm{pS}_{0}$ can be estimated as solubility in the acidic region of the curve $\left(\mathrm{pH} \ll \mathrm{p} K_{\mathrm{a}}\right)$. Select $\mathrm{H}^{+}+\mathrm{A}^{-} \leftrightarrows \mathrm{HA}, \mathrm{HA} \leftrightarrows \mathrm{HA}(\mathrm{s})$, and $\mathrm{nA}^{-} \leftrightarrows \mathrm{A}_{n}{ }^{\mathrm{n}}{ }^{-}$as the three equilibria to consider in the model, and associate $\mathrm{p} K_{\mathrm{a}}$ and $\mathrm{p} S_{0}$ with the first two equations. Take a guess on the third constant, e.g., assume it to be 3 (log units).

6. It is possible that more than one mechanism is associated with the solubility profile. Therefore, a combination of the above steps may be needed.

7. If the curve levels off in the alkaline solution $\left(\mathrm{pH} \gg \mathrm{p} K_{\mathrm{a}}\right)$, as in Figure 5 , then a salt may have precipitated in alkaline solution. It needs to be ascertained that the effect is not due to the complete dissolution of solid, as in Figures 5a,e,f. Enter the appropriate equilibrium expression along with a guess of the value of the constant.

8. Having initial estimates of constants corresponding to proposed equilibrium reactions, the model is ready for weighted nonlinear regression, a procedure described elsewhere [2,6]. The iterative refinement will test the consistency between the data and the model. If the agreement is not good 
(root-mean square error $>>0.1$ ), then the model may be modified and the refinement process repeated, until no further improvements are evident.

(C)2014 by the authors; licensee IAPC, Zagreb, Croatia. This article is an open-access article distributed under the terms and conditions of the Creative Commons Attribution license (http://creativecommons.org/licenses/by/3.0/) (cc) BY 